\title{
Identificação e Características Culturais de Espécies do Gênero Aspergillus Isoladas de Sementes de Feijão no Estado da Paraíba
}

\author{
Vanilde Benicio $^{1}$, Egberto Araújo ${ }^{2}$, Francisca Maria de Souto ${ }^{2}$, Maria José Benicio ${ }^{1} \&$ Délcio C. Felismino ${ }^{1}$ \\ 'Departamento de Farmácia e Biologia, Centro de Ciências Biológicas e da Saúde, Universidade Estadual da Paraíba, \\ CEP 58.100-001, Campina Grande, PB, Fax (083) 341-4509; ${ }^{2}$ Departamento de Fitotecnia, Centro de Ciências Agrárias, \\ Universidade Federal da Paraíba, Cx. Postal 42, CEP 58.397-000, Areia, PB, Fax (083) 362-2259, e-mail: \\ egberto@cca.ufpb.br
}

(Aceito para publicação em 16/10/2002)

Autor para correspondência: Egberto Araújo

BENICIO, V., ARAÚJO, E., BENICIO, M.J. \& FELISMINO, D.C. Identificação e características culturais de espécies do gênero Aspergillus isoladas de sementes de feijão no Estado da Paraíba. Fitopatologia Brasileira 28:180-183. 2003.

\section{RESUMO}

A partir de sementes de feijão (Phaseulus vulgaris) armazenadas no estado da Paraíba, foram isolados os fungos Aspergillus flavus, A. fumigatus, A. lucknowensis, A.niger, A.ochraceus e A. parasiticus. Os fungos foram identificados com base nas características culturais exibidas em meio de Czapek-Agar e morfológicas através de microscópio ótico composto. No oitavo dia de crescimento em meio de BDA, cada espécie apresentou diferenças quanto à curva de crescimento, taxa de crescimento durante o período de incubação e diâmetro das colônias no oitavo dia de acordo com a procedência das amostras de sementes.

Palavras-chaves adicionais: Phaseolus vulgaris, patologia de sementes.

\section{ABSTRACT}

Identification and cultural characteristics of Aspergillus species isolated in common bean seeds from Paraíba State, Brazil

The fungi Aspergillus flavus, A. fumigatus, A. lucknowensis, A.niger, A.ochraceus and A. parasiticus were isolated from common bean (Phaseolus vulgaris) seeds produced and stored by growers in the State of Paraíba, Brazil. These fungi were identified according to cultural characteristics on Czapek-agar medium and the structures viewed under compound microscope. The development of each fungal species on Potato-Dextrose-Agar (PDA) medium presented differences for colony diameter, curve and rate of growth according to the seed samples from which were obtained.
Espécies do gênero Aspergillus foram obervadas ocorrendo em sementes de feijão (Phaseolus vulgaris L.) procedentes do estado da Paraíba (Araújo et al, 1980; Bruno et al, 1982; Souto, 1995). O presente trabalho foi realizado com o objetivo de identificar essas espécies e analisar algumas variáveis relativas às características culturais das mesmas.

Amostras de sementes de feijão cv. Carioquinha foram coletadas de sementes armazenadas, em 1996, por pequenos agricultores dos municípios de Areia (microrregião do Brejo), Esperança e Lagoa Seca, (microrregião do Agreste) e, Araruna e Cacimba de Dentro (microrregião do Curimataú). Foram analisadas 200 sementes por amostra, sendo essas subdivididas em grupos de dez unidades, distribuídas igualmente. As sementes foram plaqueadas em método de Blotter test (Neergaard, 1979) e incubadas durante oito dias em câmara (temperatura $=22 \pm 2{ }^{\circ} \mathrm{C}$ ), sob regime de iluminação com fotoperíodo de $12 \mathrm{~h}$, utilizando-se lâmpadas fluorescentes de 40 Watts. Após esse período de incubação, as sementes foram examinadas sob microscópio estereoscópio. A partir das colônias do gênero Aspergillus, discos de micélio de aproximadamente $3 \mathrm{~mm}$ foram retirados e, em seguida, plaqueados em meio de cultura Czapek-agar. As placas foram incubadas sob as condições citadas anteriormente. Os estudos das características culturais e morfológicas das espécies de Aspergillus foram confrontadas com aquelas descritas por Raper \& Fennel (1965) e Singh et al. (1991). Para cada espécie identificada, foi escolhida aleatoriamente uma colônia representante da amostra de semente que a originou, retirandose da mesma um disco de $3 \mathrm{~mm}$ contendo micélio, o qual foi transferido para o centro de uma placa de Petri contendo BDA. Foram empregadas quatro repetições por isolado e a incubação permaneceu sob a mesma condição referida anteriormente. A partir do segundo e até o oitavo dia de incubação, foram realizadas medições dos diâmetros das colônias, com auxílio de uma régua milimetrada, em dois sentidos diametralmente opostos. Foram consideradas as seguintes variáveis: diâmetro das colônias no oitavo dia de incubação e a taxa de crescimento micelial, correspondendo esta última ao coeficiente de regressão (b) obtido da equação $\mathrm{y}=\mathrm{a}+\mathrm{bx}$, relativo aos diâmetros (y) plotados durante os dias de incubação (x), sendo "a" o diâmetro inicial. Na análise estatística (delineamento inteiramente casualizado) as médias das variáveis foram comparadas pelo teste de Tukey ao nível de 5\% de probabilidade. 
Foram identificadas espécies já reportadas em sementes de feijão: Aspergillus flavus Link (Dimitrov et al., 1987; Weindenbörner \& Hindorf, 1989; Braccini \& Dhingra, 1996; Chisholm \& Coates-Beckford, 1997), A. fumigatus Fresenius (Dimitrov et al., 1987), A. niger van Tieghem, (Araújo et al., 1980; Bruno et al., 1983; Araújo et al., 1983; Mendes et al. 1989; Weindenbörner \& Hindorf, 1989; Braccini \& Dhingra, 1996; Chisholm \& Coates-Beckford, 1997); A. ochraceus Wilhelm (Dimitrov et al., 1987; Gupta et al., 1992); A. lucknowensis Rai, Tewari \& Agarwal e A. parasiticus Speare, observadas em sementes de outras plantas (Singh et al., 1991). Para algumas dessas espécies foram verificadas tendências de crescimento diferentes (Figura 1), de acordo com as amostras de sementes de onde foram isoladas. Os diâmetros das colônias no oitavo dia de incubação para os A. flavus, A. fumigatus, A. niger e A. parasiticus quase chegaram a ocupar toda a área da superfície do meio de cultura (Tabela 1). Mesmo assim foram encontradas diferenças estatisticamente significativas entre os isolados das diferentes amostras de sementes, com exceção das espécies A. niger e A. ochraceus. Os isolados de A. lucknowensis apresentaram os menores diâmetros das colônias porém todos foram diferentes entre si. As taxas de crescimento micelial das espécies apresentaram diferenças significativas entre os isolados, sendo o observado decorrente das diferentes tendências de crescimento (Figura 1). Para essa variável também os isolados de A. lucknowensis apresentaram os menores valores. A variabilidade dentro de cada espécie é um fenômeno genético comum e, conseqüentemente, também observado naqueles que ocorreram em sementes (Martins, 1978; Araújo, 1988).
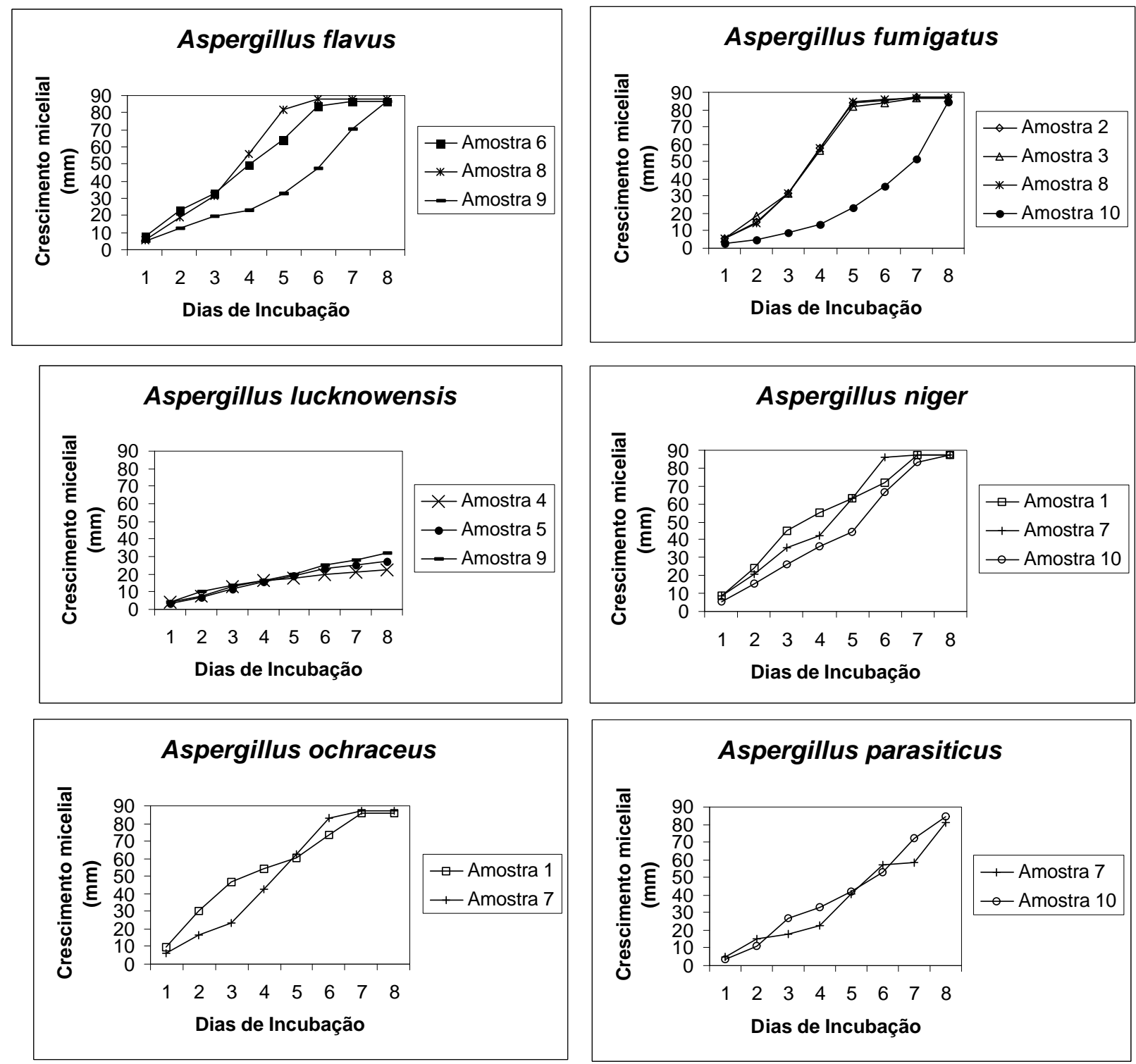

FIG. 1 - Curvas de crescimento micelial das espécies de Aspergillus isoladas das amostras de sementes de feijão (Phaseolus vulgaris), em meio de BDA, Areia, PB, 1996. Origem das amostras (municipios/microrregião): 1, 2 e 7 - Areia/ Brejo; 3 e 4 - Esperança/Agreste; 5, 6 e 8 - Lagoa Seca/Agreste; 9 - Araruna/Curimatau; e, 10 - Cacimba de Dentro/Curimatau. 


\section{Benicio et al.}

TABELA 1 - Diâmetro das colônias de espécies de Aspergillus isoladas de amostras de sementes de feijão (Phaseolus vulgaris) coletadas em três microrregiões do Estado da Paraíba. 1996

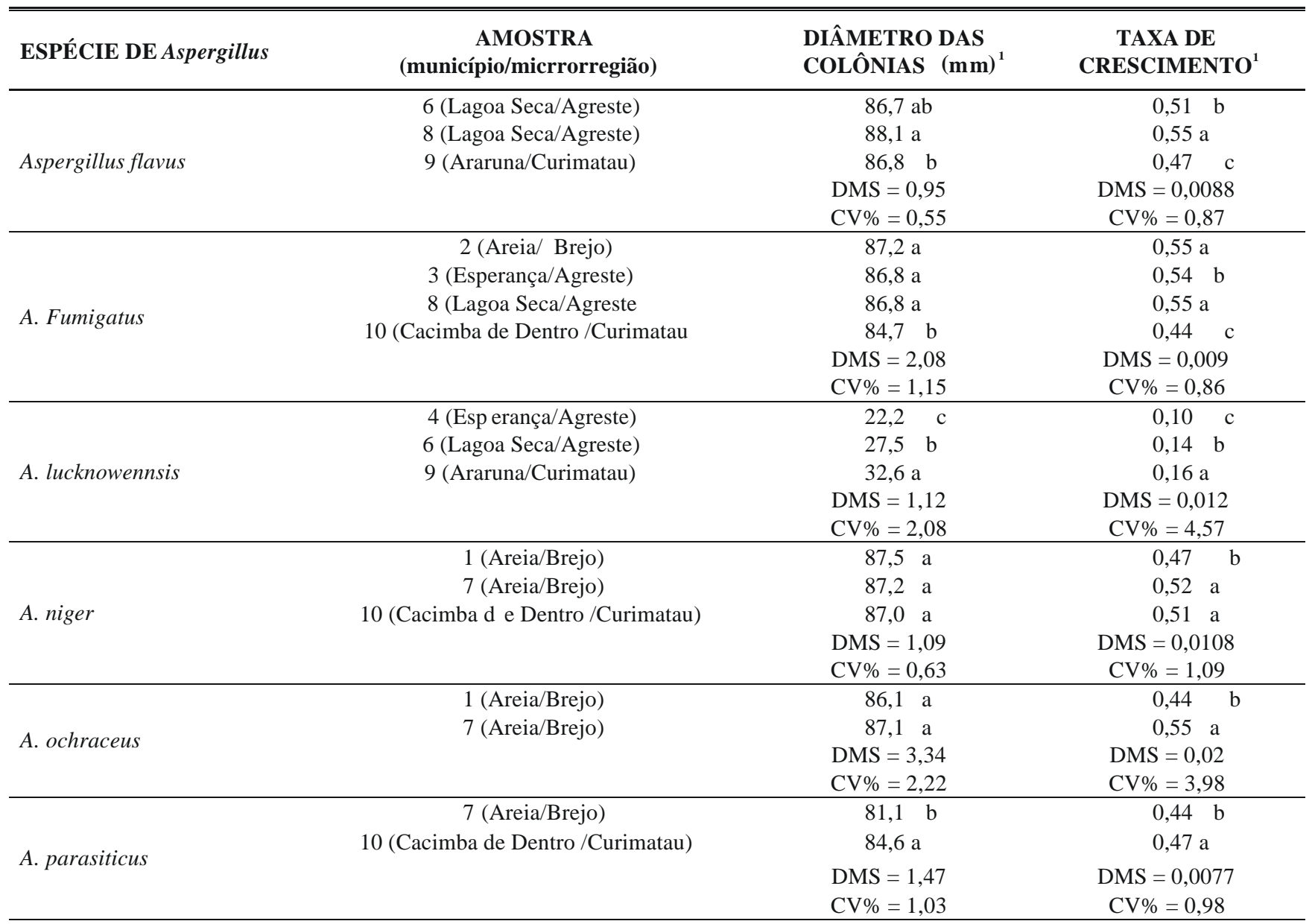

${ }^{1}$ Médias seguidas da mesmas letras nas colunas não diferem entre si ao nível de $5 \%$ de probabilidade pelo teste de Tukey.

\section{REFERÊNCIAS BIBLIOGRÁFICAS}

ARAÚJO, E., ALCÂNTARA, R. de L., SOUZA. F.A.V., ALMEIDA, F.A.C., CARVALHO, J.L., LIMA, A.A.A., LIMA, A.L., MENEZES NETO, J. \& PONTES, V.A. Fungos associados a sementes de feijão obtidas em diferentes municípios da Paraíba. Revista Brasileira de Sementes 2:109-115. 1980.

ARAÚJO, E. Resistência do feijoeiro (Phaseolus vulgaris L.) à infecção causada por Colletotrichum lindemuthianum (Sacc et Magn) Scrib. e a sua transmissão pelas sementes. (Tese de Doutorado).Viçosa. Universidade Federal de Viçosa. 1988.

BRACCINI, A.L. \& DHINGRA, O.D. Avaliação da incidência de fungos de armazenamento em sementes de soja (Glycine max (L.) Merril) e feijão (Phaseolus vulgaris L.) em meio seletivo. Revista UNIMAR 18:487-493. 1996.

BRUNO, R.de L.A., ARAÚJO, E., MELO, S.A.P.\& MENEZES, M. Influência da aplicação de produtos químicos sobre o controle de doenças, produtividade e micoflora nas sementes do feijoeiro (Phaseolus vulgaris L.) no Estado da Paraíba. I Tratamento de Sementes. Agropecuária Técnica 3:38-51. 1982.

CHISHOLM, F.V. \& COATES-BECKFORD, P.L. Fungi associated with seeds of three legume species in Jamaica and seed germination at harvest and after storage. Tropical Agriculture 74:121-127. 1997. CHRISTENSEN, C.M.. Microflora and seed deterioration. In: Roberts, E. H. (Ed.) Viability of seeds. London. Syracuse University Press. 1972. pp.59-93.

DHINGRA, O.D. Prejuízos causados por microorganismos durante o armazenamento de sementes. Revista Brasileira de Sementes7:139144. 1985.

DIMITROV, M., NIKOLCHEVA, M. \& DRENSKA, E. Studies on the presence of Aspergillus in grain of wheat, maize and bean. Pochvoznanie, Agrokhimiya i Rastilelna Zushchita 22:83-89. 1987.

GUPTA, S.K., SHYAM, K.R. \& DOHROO, N.P. Addition to seed mycoflora of french bean (Phaseolus vulgaris L.). Plant Disease Reporter 7:271. 1992.

MARTINS, M.C.D.P. Heterogeneidade de amostras de sementes comerciais do fejoeiro (Phaseolus vulgaris L.) a raças fisiológicas de Colletotrichum lindemuthianum (Sacc e et Magn) Scrib. e de Uromyces phaseolis var. typica Arth. (Tese de Mestrado). Viçosa. Universidade Federal de Viçosa. 1978.

NEERGAARD, P. Seed Pathology. 2 ed. London: Mc Millan. 1979. RAPER, K.B. \& FENNEL, D.I. The genus Aspergillus. Baltimore, ed.Williams and Wilkinson Co. 1965. 
Identificação e características culturais de Aspergilli isolados de...

SINGH, K., FRISVAD, J.C., THRANE, U. \& MATHUR, S.B. An illustrated manual on identification of some seed-borne Aspergilli, Fusaria, Penicillia and their micotoxins. Copenhague. Danish Government Institute of Seed Pathology for Developing Countries. 1991.

SOUTO, F.M. Micoflora das sementes de feijão (Phaseolus vulgaris L.), caupi (Vignna unguiculata (L.) Walp.) e fava (Phaseolus lunatus
L.) produzidas em três microregiões do Estado da Paraíba, durante dois anos agrícolas. (Tese de Mestrado). Areia. Universidade Federal da Paraíba. 1995.

WEINDENBÓRNER, M. \& HINDORF, H. Fungi isolated from protein enriched seeds and pods with special emphasis on the genus Aspergillus. Seed Science and Technology 17:383-389. 1984. 